\title{
Resenha \\ O teólogo e a pandemia: a busca por não-respostas
}

\section{The theologian and the pandemic: the search for non-answers}

\section{El teólogo y la pandemia: la búsqueda de no respuestas}

Henrique Mata de Vasconcelos*

WRIGHT, N. T. Deus e a pandemia: uma resposta cristã sobre o coronavírus e suas consequências. Trad. Elissamai Bauleo. Rio de Janeiro: Thomas Nelson Brasil, 2020. 144p. 11x15 cm. ISBN 978-65-56890-48-7.

Nicholas Thomas Wright (1948), conhecido N. T. Wright, é um notório teólogo britânico. Foi bispo de Durham entre 2003 e 2010 e é um dos expoentes da nova perspectiva sobre Paulo, sendo o primeiro a utilizar esse termo. É considerado como um dos mais influentes especialistas no Novo Testamento da sua geração inglesa. Na atualidade, é professor pesquisador na Universidade de St Andrews e pesquisador sênior do Wycliffe Hall, na Universidade de Oxford. Editoras como a Paulus, Loyola e Thomas Nelson Brasil, entre outras, publicaram traduções de algumas de suas obras.

\footnotetext{
* https://orcid.org/0000-0002-4999-0397. Faculdade Jesuíta de Filosofia e Teologia Belo Horizonte. Mestre (2021) e Doutorando em Teologia Sistemática, como bolsista CAPES, na Faculdade Jesuíta de Filosofia e Teologia. Bacharel (2018) em Teologia pelo Centro Universitário Metodista Izabela Hendrix e pós-graduado (2020) em Profetismo e Apocalíptica pela Universidade Metodista de São Paulo. Graduando em Filosofia na Universidade Federal de Minas Gerais. henriquemata97@hotmail.com .
} 
Em face da conjuntura pandêmica em que nos encontramos, numa tentativa de compreender a nossa situação à luz da fé cristã, teólogos e teólogas estão refletindo acerca dela. Nesse horizonte, encontramos o pequeno e rico livro de Wright. Conforme o seu prefácio, que vem acompanhado dos agradecimentos, o livro é escrito como uma continuação de um seu artigo escrito no princípio da pandemia para a revista Time. O A. visa contribuir, com sabedoria e biblicamente, diante da atual situação. Ele confessa que também experienciou fortes emoções no decorrer das semanas de confinamento, mas que pensa ser essencial que as nossas reações sejam mantidas dentro dos limites bíblicos, afirmando que foi isso que ele tentou fazer nos seus textos. Desde já, Wright afirma que não oferece soluções para as questões surgidas no contexto atual, nem traz aprendizados ou direcionamento de ações. Antes, tenta dissuadir os seus leitores em relação às reações automáticas e impulsivas e se propõe a refletir, mesmo que, para ele, de maneira insatisfatória e ampla, sobre a situação. Então o teólogo, seguindo o que havia abordado no artigo da revista Time, recomenda um tempo de lamento e, indo além, também de autocontrole. Isso, segundo ele, para que não cheguemos a soluções precipitadas e para que possamos discernir as soluções que chegarão pela graça divina. Assim, expressa a sua esperança de que surgirá uma luz, após um tempo de dedicação à oração e ao lamento. Aqui já notamos claramente que o A. tem uma grande preocupação pastoral, dada à dura realidade presente, de abrandar as emoções e direcionar os cristãos.

No primeiro capítulo, Por onde comę̧amos, o A. indaga se as previsões exageradas de milhões de mortes por outros vírus que superamos, como o SARS, mesmo após um tempo de preocupação, estariam se repetindo. O que hoje vemos que não. Logo depois, como um inglês, ele destaca que os britânicos e americanos só reconheceram a insegurança mundial diante do coronavírus quando ele chegou em Londres e em Nova Iorque. Assim, não há mais nenhum lugar seguro, como havia em guerras. Wright destaca diferentes posturas na busca de compreender o que está ocorrendo, fazendo uma relação com o mundo antigo e os equivalentes no mundo moderno. Alguns responsabilizam a ira dos deuses, outros vêem como algo já determinado, outros como uma arbitrariedade e, outros, como a imperfeição de um mundo que é apenas uma sombra. Além da maioria dos ocidentais modernos que, à espera do fim dessa crise, como qualquer outra, querem conforto, isolamento e entretenimento, e dos cristãos que pensam ser peregrinos, que querem ser sensíveis, mas não abrem mão das portas abertas das igrejas. Porém, encontramos situações bem 
mais graves: em campos de refugiados, e lugares semelhantes, o sofrimento e a tristeza se agravam e a receosa pergunta do porquê surge. Segundo ele, o importante não é se perguntar o porquê, mas o que podemos fazer diante dessa realidade, exemplificando inúmeras pessoas que responderam apropriadamente a essa segunda pergunta. Algumas até morreram por causa disso. Assim, ele sublinha a ética cristã de cuidado, martírio e sacrifício em prol dos outros que a nossa cultura herdou, espelhada em Jesus e herdeira da ética judaica, e que são fundamentos de ações sociais (Tom Holland, Dominion), destacando algumas contemporâneas em combate ao vírus.

O britânico destaca as inúmeras teorias de conspirações, preferidas pelos simpatizantes de guerras culturais, que se espalham rapidamente como o vírus, com a fácil responsabilização do outro, e a necessidade de cristãos por respostas reativas, à luz de antigas compreensões instintivas. Segundo Wright, “também existem teorias especificamente 'cristãs' de conspiração. Alguns pensam saber exatamente o que deu errado e o que Deus está tentando dizer com tudo isso. Alguns andam dizendo, ansiosamente, que este é o sinal do fim” (p. 21). Ele ainda expõe a indústria apocalíptica, que usa trechos da Bíblia e o pietismo fundamentalista para criar um enredo de terror. “É bastante platônico: 'ir para o céu' é o objetivo, deixando o mundo para trás, com seu Armagedom. E agora o coronavírus é aclamado como o sinal de que tudo está para acontecer" (p. 22). Uns cristãos pensam que a pandemia é uma brecha para evangelizar e outros que ela é causada pela ira de Deus, seguindo "essa linha de raciocínio como pretexto para culpar seus objetos de ódio costumeiros, afirmando que é tudo culpa deste e daquele, cujo estilo de vida desaprovam" (p. 23).

No segundo capítulo, Lendo o Antigo Testamento, Wright destaca as diferentes perspectivas do AT sobre as atrocidades e sofrimentos que o povo de Israel passou, ligando-os a ecos contemporâneos dessas: os pragmatistas, com a sua causa e efeito, os moralistas indiferentes e os que enfatizam problemas secundários importantes e os realistas. Para ele, todos aproveitam a oportunidade para dar voz ao que já pensavam. Assim, aponta alguns textos do AT, começando pelos que apontam uma causalidade das tragédias, decorrentes de pecados. Porém, ele também aponta textos que expressam que o mal e o sofrimento se fazem presentes sem motivo algum, afirmando ser uma posição mais equilibrada. Além de citar e falar de alguns Salmos (44, 73 e 88), o A. lembra-se de Jó e de seu sofrimento arbitrário. Então, afirma que há dois enredos principais no AT, a história da aliança do 
Deus de Israel com seu povo e uma outra narrativa mais profunda sobre a boa criação divina e de um poder tenebroso que a tenta destruir. Esse ele afirma não compreender. Ele afirma que, "ao nos vermos em circunstâncias terríveis, injustiças grosseiras e pragas horrendas [, entre outras mazelas,] devemos lamentar, expor a nossa queixa, declarar o nosso caso e deixá-lo perante Deus" (p. 38).

No terceiro capítulo, Jesus e os Evangelhos, o A. busca resgatar a centralidade de Jesus como sinal do reino e da necessidade de arrependimento e combater excessos de imaginários apocalípticos, isto é, atraentes e falsas leituras de Armagedom que são feitas diante de catástrofes, como a atual pandemia. Jesus atuou como profeta, mas o seu principal anseio era ver a graciosa obra de Deus na vida do povo e, assim, terremotos, fomes, guerras e afins, não são a pista de sua ação no mundo, e sim Jesus; ou obras moldadas pela sua vida. É a partir dele que temos que nos atentar, rever e arrepender de nossas atitudes e sistemas antirreinos, que vão contra o ser humano, a vida e o meio ambiente, e não por causa das tragédias. O outro ponto central do capítulo é mostrar que o controle e a soberania de Deus é diferente da imagética popular. Na cruz é mostrado o reino, o controle e a soberania de Deus. Além disso, vemos Jesus chorando e sofrendo, no Getsêmani, na cruz e na morte do seu amigo. É por essa chave que devemos ver o poder e o controle divino. Jesus não parou quando disseram que ele poderia ter impedido a morte de Lázaro (Jo 11,21.32.37). Antes, ele chora e segue adiante. "Jesus não olha para trás para ver o que pode ou não ter acontecido. Pessoas o culparam, mas ele não culpará ninguém. Confiou em seu Pai, e agora olha para o futuro, a fim de ver o que deve, agora, acontecer. E o meio para esse fim é através das lágrimas" (p. 60). Segundo Wright, é com esse eco que devemos olhar para as questões do coronavírus.

No quarto capítulo, Lendo o Novo Testamento, Wright mostra que nesse testamento, os cristãos não procuravam saber o motivo das mazelas, mas o que poderiam e iriam fazer diante delas. Eles estavam preocupados com a missão, que é ser a imagem de Deus. O teólogo também mostra que eles não utilizavam as tragédias para chamar as pessoas ao arrependimento. Pelo contrário, a pregação era baseada na pessoa de Jesus. Além disso, destaca que o papel da Igreja é orar, pois compartilhamos do gemido da criação (Rm 8). E, mesmo que estejamos sem saber de nada na nossa situação atual, o próprio Deus, o Espírito, está gemendo também. "Essa é a nossa vocação: orar, talvez sem palavras, no lugar onde o mundo sente dor" (p. 88). Mas, além do 
lamento mesmo sem palavras, defende que temos trabalho a fazer diante da pandemia. Por meio do seu povo, Deus age no mundo, mostrando sua justiça e misericórdia a um mundo abatido.

Por fim, o quinto capítulo, Para onde vamos daqui?, é um texto conclusivo, reflexo das reflexões anteriores. O A. traz algumas considerações, reflexões e instruções pastorais a partir do que já havia tratado e além, sobre como devemos agir e viver nos tempos bons e nos ruins. Uma parte importante do texto é a sua equilibrada posição sobre o fechar ou não das Igrejas na pandemia, elucidando que Jesus está além das paredes, mas que elas são importantes sinais de Deus para o mundo. Assim, demonstra sua preocupação de que os cristãos sigam a tendência da visão da modernidade a respeito da Igreja, e a abandonem. Para ele, estamos num exílio. Porém, não podemos nos esquecer de Jerusalém, isto é, da Igreja. O teólogo demonstra a sua preocupação com os mais vulneráveis e com os pobres, que vivem em países emergentes ou em campos de refugiados, nos quais o distanciamento social é impossível. Ele se mostra apreensivo com o que ocorrerá após a pandemia com eles, se ainda continuarão sendo jogados contra a parede. Então, sublinha a necessidade de estadistas e autoridades sábias, para não voltarmos ao mesmo normal de antes.

Em geral, Wright cumpre bem o seu objetivo pastoral. Em relação à tradução, o trabalho foi realizado em linguagem acessível, seguindo o original (God and the pandemic, SPCK, 2020), visando o público cristão amplo. Um ponto de destaque para a tradução é a contextualização, na medida do possível, das versões bíblicas que Wright cita. Quando houve a identificação do sentido das traduções, a tradutora cita versões brasileiras como exemplo (p. 90,93). Mas mesmo quando não encontrou uma tradução equivalente em português, a tradutora traduziu a versão citada por Wright e destacou no texto que se tratava de uma tradução inglesa (p. 95). São detalhes simples que enriquecem a obra. Nesse sentido, também temos a inserção da referência bíblica em uma citação que o A. não referenciou (p. 130), o que facilita para o leitor a localização do texto na sua Bíblia. Apenas sublinho que a palavra "instei" (p. 101) não soou muito bem. Penso que o "I have urged you", do original, poderia ter sido traduzido melhor e de forma mais acessível e agradável com outra expressão mais simples e clara, como "eu tenho insistido" ou "persisti". 